\title{
Advanced Reservoir Characterization and Evaluation of CO2 Gravity Drainage in the Naturally Fractured Spraberry Reservoir
}

\author{
Quarterly Report \\ July 1 - September 30, 1997

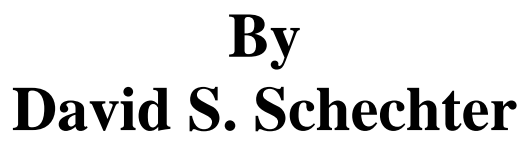

Work Performed Under Contract No.: DE-FC22-95BC14942

For

U.S. Department of Energy

Office of Fossil Energy

Federal Energy Technology Center

P.O. Box 880

Morgantown, West Virginia 26507-0880

By

New Mexico Petroleum Recovery Research Center

New Mexico Institute of Mining and Technology

801 Leroy Place

Socorro, New Mexico 87801 


\section{Disclaimer}

This report was prepared as an account of work sponsored by an agency of the United States Government. Neither the United States Government nor any agency thereof, nor any of their employees, makes any warranty, express or implied, or assumes any legal liability or responsibility for the accuracy, completeness, or usefulness of any information, apparatus, product, or process disclosed, or represents that its use would not infringe privately owned rights. Reference herein to any specific commercial product, process, or service by trade

name, trademark, manufacturer, or otherwise does not necessarily constitute or imply its endorsement, recommendation, or favoring by the United States Government or any agency thereof. The views and opinions of authors expressed herein do not necessarily state or reflect those of the United States Government or any agency thereof. 
Introduction

Natural fractures exert a strong influence over oil production in Spraberry Trend Area reservoirs in the Permian Basin of west Texas. The importance of the fracture network has been known since the 1950s, but until recently, there has been very little detailed study of the fractures themselves. In 1996, a horizontal Spraberry well was cored as part of a DOE Class III Field Demonstration Project. Fractures from the horizontal core as well as other fractures encountered in vertical Spraberry cores were analyzed in detail for information on both large scale features including orientation and spacing and small-scale features such as the relationships between fracture mineralization and matrix rock composition.

At least three sets of fractures are found within the upper and middle Spraberry cores. These sets have distinct orientations, spacing, mineralization, distribution with respect to lithology, and surface characteristics (Lorenz, 1997). Fractures found in the 1U zone of the upper Spraberry have a NE strike, and tend to be partly mineralized with barite, quartz, and dolomite. Distribution of these mineral phases can greatly affect conductivity between the fractures and the rock matrix. The $5 \mathrm{U}$ zone of the upper Spraberry contains fractures with NNE and ENE orientations. The NNE set of fractures has stepped fracture surfaces indicating a shear origin, and minor amounts of quartz and dolomite mineralization. The ENE fracture set has smooth planar surfaces of tension origin with some calcite mineralization present. Natural fractures in black shales overlying both the $1 \mathrm{U}$ and the $5 \mathrm{U}$ have an ENE orientation similar to unmineralized fractures in the 5U. No fractures were encountered in similar shales underlying reservoir zones. A set of hairline fractures, most completely healed with calcite cement was also found in some Middle Spraberry cores. The unique nature of each of these fracture sets implies that fracturing probably occurred as several separate events and indicates that the Spraberry Formation has undergone a more complex stress history than might be construed from its fairly flat-lying nature.

\section{Progress}

During the past several months, work has continued on characterizing fractures at the microscopic scale by means of thin section petrography, electron microprobe analysis, and scanning electron microscopy.

Work done so far seems to confirm the early conclusion that there are indeed three distinct fracture sets, and it is possible to speculate on the relationships between these three sets. 


\section{U Fractures}

The major fracture orientation seen in 1U cores is N42E (Fig. 1). This fracture orientation is common only in the $1 \mathrm{U}$ and seen rarely in the $5 \mathrm{U}$. Spacing of fractures with this orientation has a Gaussian distribution (Fig. 2), with a maximum of $7 \mathrm{ft}$. and an average of about $3.2 \mathrm{ft}$. $1 \mathrm{U}$ fractures are slightly to heavily mineralized, particularly towards the upper parts of the formation. Barite is the only mineral phase easily visible to the naked eye, but examination in thin section and SEM indicates the presence of abundant quartz and some dolomite as additional fracture-filling minerals. In the megascopic view, this set of fractures has fairly smooth and planar surfaces that show no evidence of movement or shear.

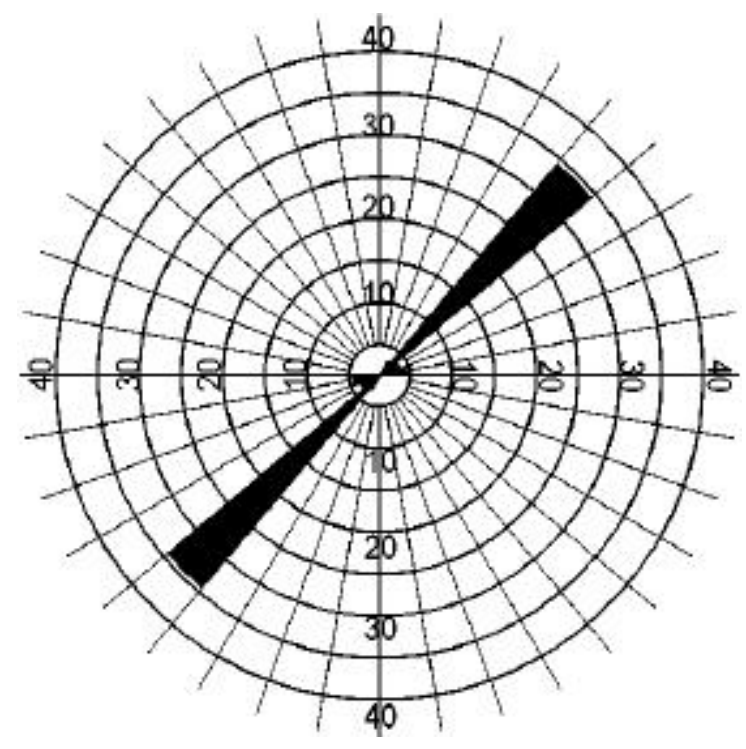

FRACTURE SPACING, 1U, NE SET

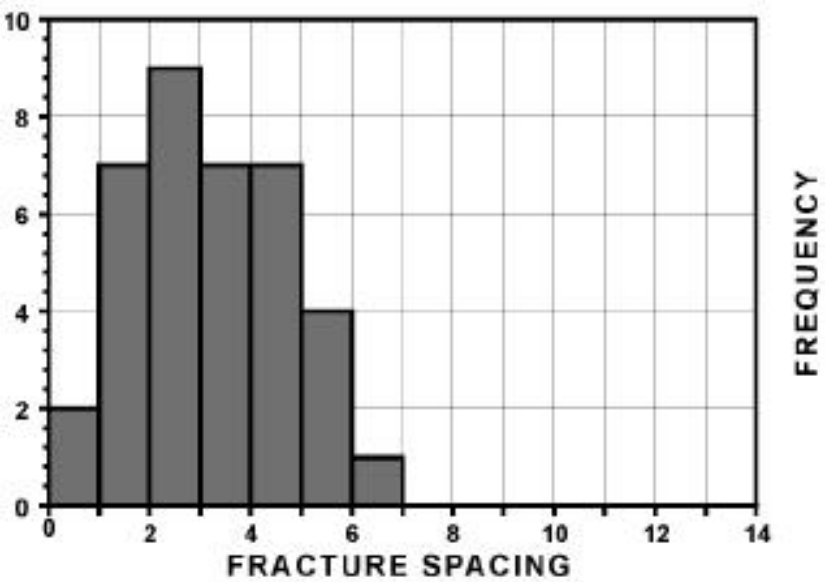

Figure 1. Orientation of $1 \mathrm{U}$ fractures shows a strong N42E trend, with only a few fractures having a distribution of N80E.
Figure 2. 1U fracture spacing has a normal Gaussian distribution, with an average spacing of about 3 feet, and a maximum of 7 feet. 
Microscopic examination of $1 \mathrm{U}$ fracture surfaces shows that barite occurs in large crystals, up to a millimeter or more in size, with very smooth tabular faces. Barite crystals can partly to completely cover the surfaces of $1 \mathrm{U}$ fractures and appears to occlude porosity and may be responsible for reducing the crossflow of fluids and gas between rock matrix and fracture porosity (Figs. 3 and 4).

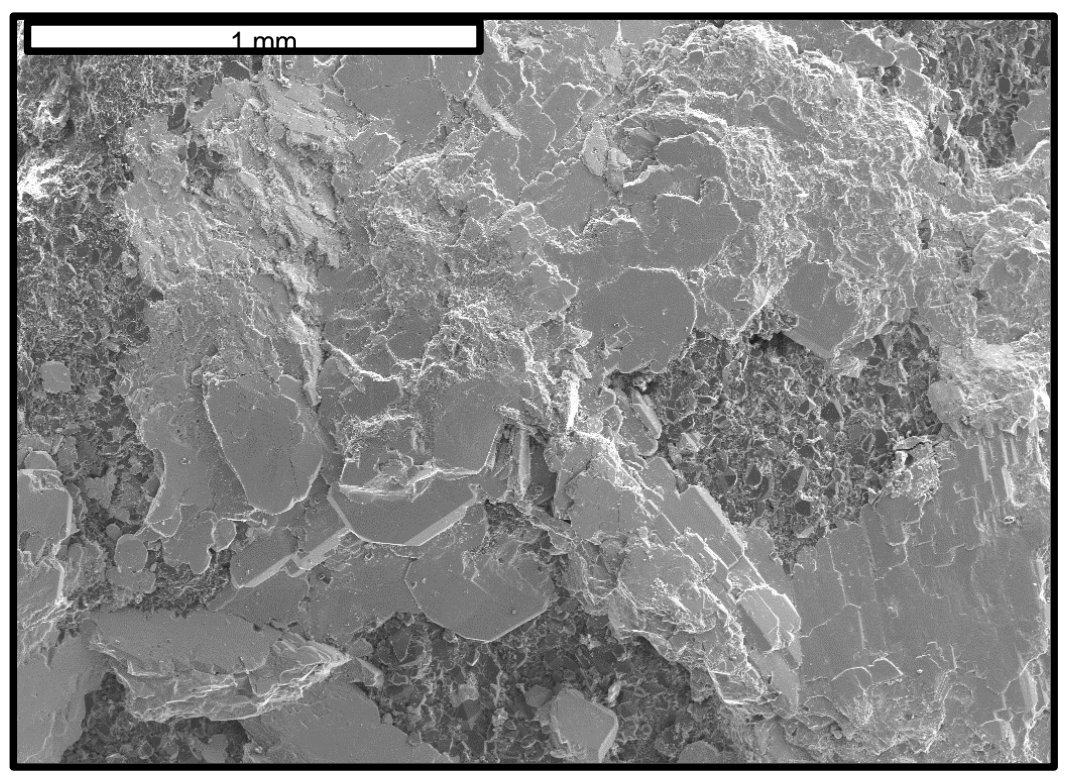

Figure 3. SEM photomicrograph of barite that is covering the surface of a $1 \mathrm{U}$ fracture. Barite is the lighter gray mineral that forms the smooth surfaces. Note how it covers most of the microporosity at the fracture surface.

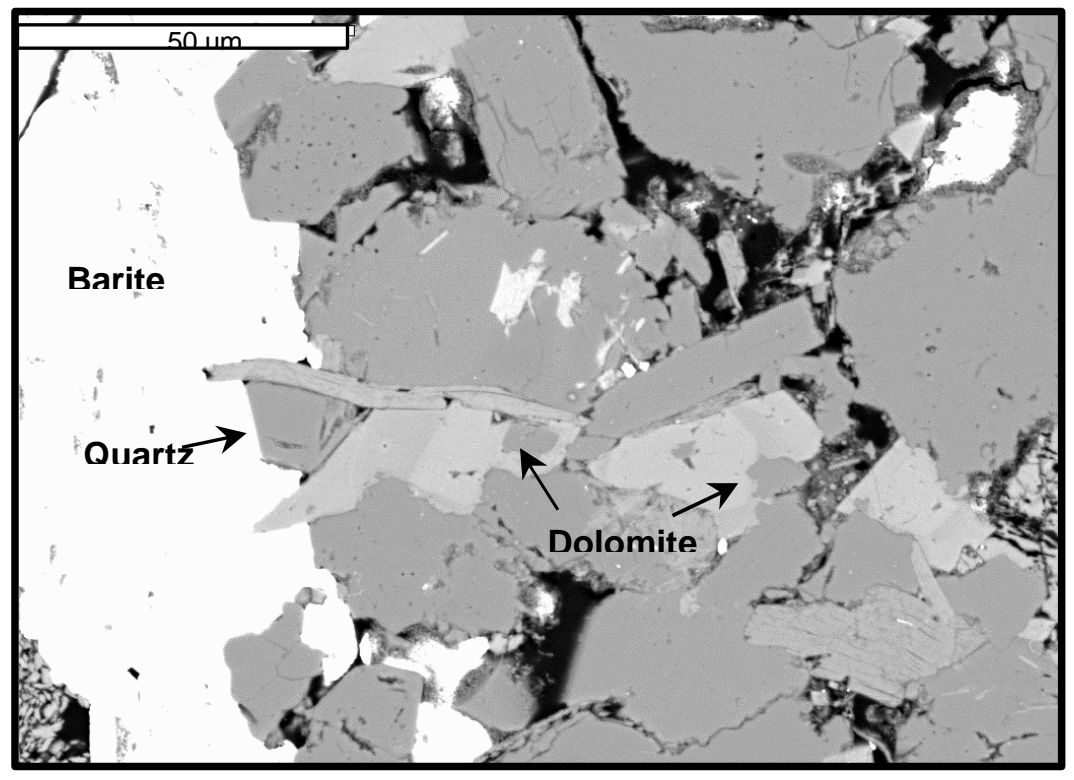

Figure 4. SEM photomicrograph of a thin section across a fracture. Photo shows various authigenic mineral phases including quartz, barite, and dolomite. The lighter mineral phases associated with the dolomite grains are ankerite (the lightest gray) and ferroan dolomite (the intermediate gray). 
Quartz and dolomite occur in varying abundance as authigenic minerals on $1 \mathrm{U}$ fracture surfaces, however their size and morphology do not seem to have the same deleterious affect on porosity. Crystal sizes of quartz and dolomite are generally commensurate with the sizes of quartz and dolomite grains within the rock matrix, about 50 microns or less for quartz and generally less than 10 microns for dolomite. Thus, they do not appear to grow over and cover pore space that connects matrix with fracture (Figs. $5 \& 6$ ). Indeed, although quartz crystals seem insignificant in terms of abundance and size, they provide numerous asperities that may prevent these fractures from closing even at reservoir pressure conditions (Fig. 7). The presence of abundant euhedrally-terminated quartz crystals demonstrates that fractures were open during certain periods of diagenesis.

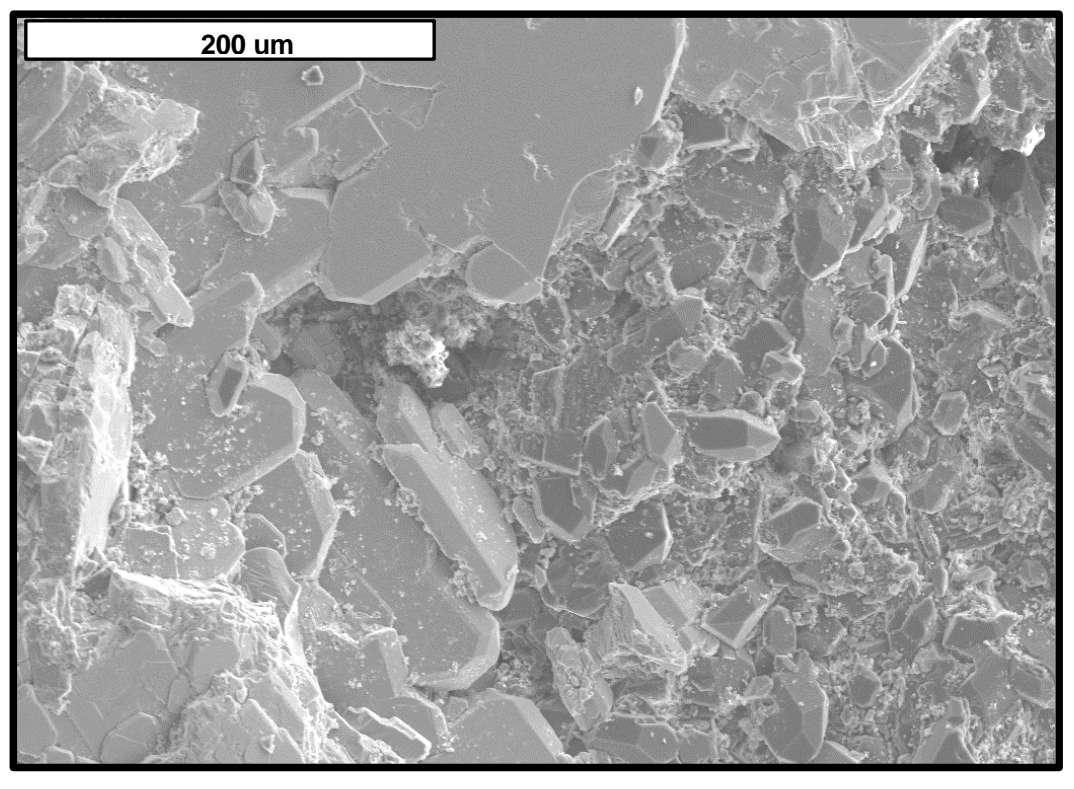

Figure 5. SEM photomicrograph of a $1 \mathrm{U}$ fracture surface that has been partly covered by barite (tabular crystals on left) and also has quartz and dolomite mineralization (small pyramid and rhombshaped crystals on right side of photo). Again, note how barite covers microporosity.

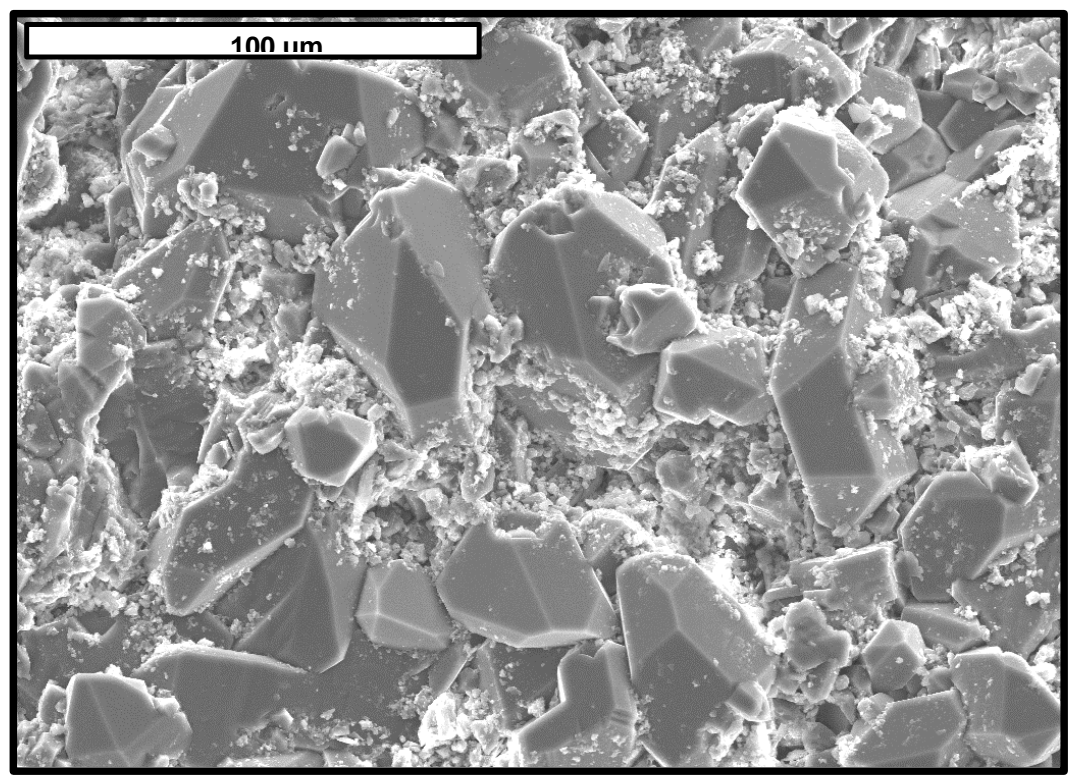

Figure 6. SEM photomicrograph of a $1 \mathrm{U}$ with quartz and dolomite mineralization. Dolomite has filled much of the intergranular pore space in this sample 


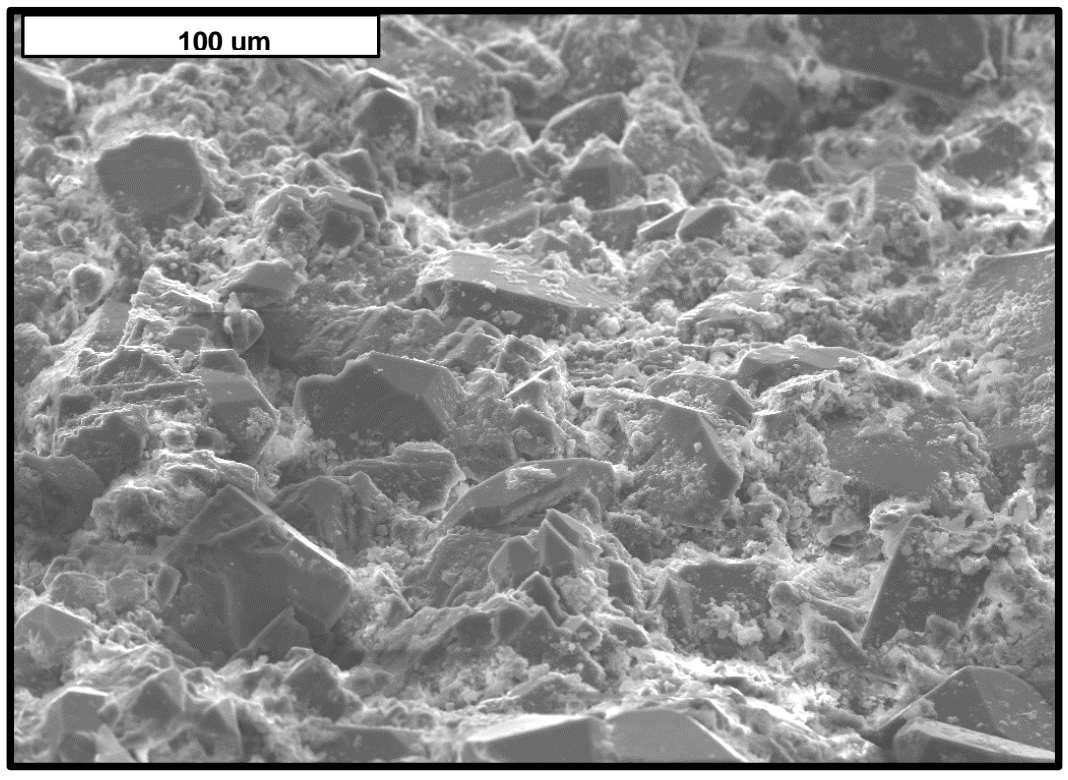

Figure 6. SEM photomicrograph showing an oblique view of a fracture surface. The quartz crystals, although small, provide significant surface asperities that help to keep fracture porosity open at depth.

In $1 \mathrm{U}$ fractures, it is apparent that fractures formed after early-stage diagenesis and dolomitization of carbonate grains and mud, but are syngenetic with some quartz precipitation and precipitation of ferroan dolomite, as both of these phases occur within matrix and within the fractures. Barite was not seen anywhere except in fractures, indicating precipitation later in the diagenetic history of the Spraberry.

\section{U Fractures}

Fractures in the $5 \mathrm{U}$ occur in two major orientations, N32E and N70E. Although at first glance, these fractures could be mistaken as a conjugate set that is almost bisected by the fracture set seen in the $1 \mathrm{U}$ unit, closer examination reveals that they are indeed two separate sets and probably distinct from $1 \mathrm{U}$ fractures as well.

One group of fractures has an orientation of N32E. These fractures have a log-normal spacing distribution and spacing is fairly narrow, with an average of about $1.6 \mathrm{ft}$ and a maximum of about $5 \mathrm{ft}$. There is no obvious mineralization on the surfaces of the N32E fractures, and the fracture surfaces appear somewhat rough and stepped, indicating some component of shear was active during their genesis. The second group of fractures has a N70E orientation. Spacing between fractures in this set is quite different than seen in the other two sets. Spacing is log normal, but skewed with a long tail. The average spacing is about $3.79 \mathrm{ft}$., but the maximum spacing is over $14 \mathrm{ft}$. and the most common spacing is less than two feet. Like $1 \mathrm{U}$ fractures, these have a smooth planar appearance with no indication of shear, but there appears to be no surface mineralization under visual examination (Figs. 7,8, \& 9). 


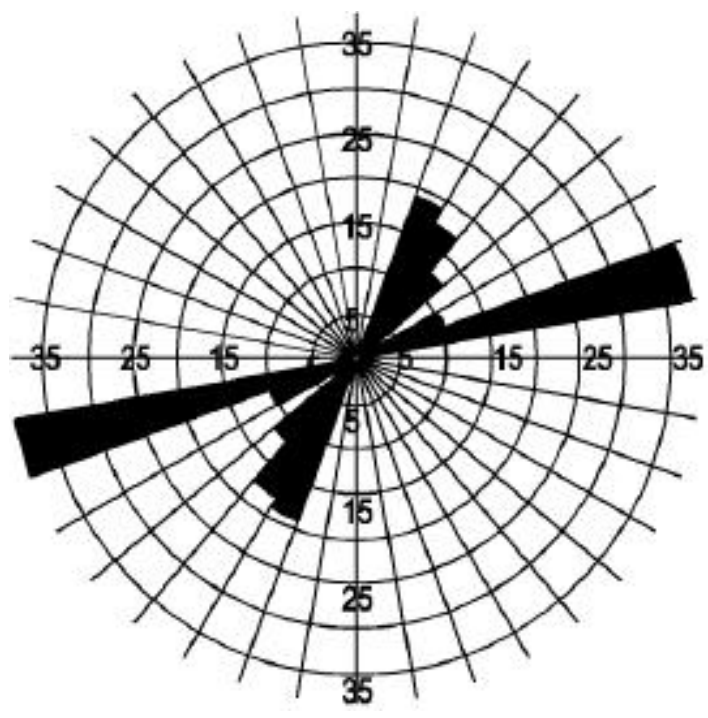

Figure 7. Fracture orientation for $5 \mathrm{U}$ fractures. There are two major orientations, one averaging $\mathrm{N} 32 \mathrm{E}$ and the other N80E.

Figure 8. Fracture spacing for $5 \mathrm{U}$ fractures with a N32E orientation. Fracture spacing is log normal, with an average of about $1.6 \mathrm{ft}$ and a maximum of around $5 \mathrm{ft}$.

Figure 9. Fracture orientation for $5 \mathrm{U}$ fractures with a N80E orientation. Spacing is normal but skewed, with a long tail. Spacings can be as much as $14 \mathrm{ft}$ or less than a few inches; the average is around $3.8 \mathrm{ft}$. 
Closer examination of $5 \mathrm{U}$ fractures shows that surface mineralization is present on these fractures, but not in the abundance of $1 \mathrm{U}$ fractures. Quartz and dolomite are both fairly common, but barite is rare. As in the $1 \mathrm{U}$, the crystal size and habit of both quartz and dolomite are commensurate with their grain sizes in the host matrix, and the mineralization probably has no adverse affect on permeability between rock matrix and fracture porosity (Figs. $10 \& 11$ ). Barite occurs as large crystals up to $1 \mathrm{~mm}$ in diameter, similar to the $1 \mathrm{U}$. But its scarcity within the $5 \mathrm{U}$, at least in this horizontal core, makes it relatively unimportant as a possible fracture seal. Barite was observed in a few $5 \mathrm{U}$ samples as large crystals within the rock matrix near pores. It appeared to have been a pore filling cement and because of its large size, it either replaced some detrital constituent of the siltstone as well, or it was filling some vacancy caused by dissolution of some precursor grains and cements, possibly detrital and authigenic carbonates.

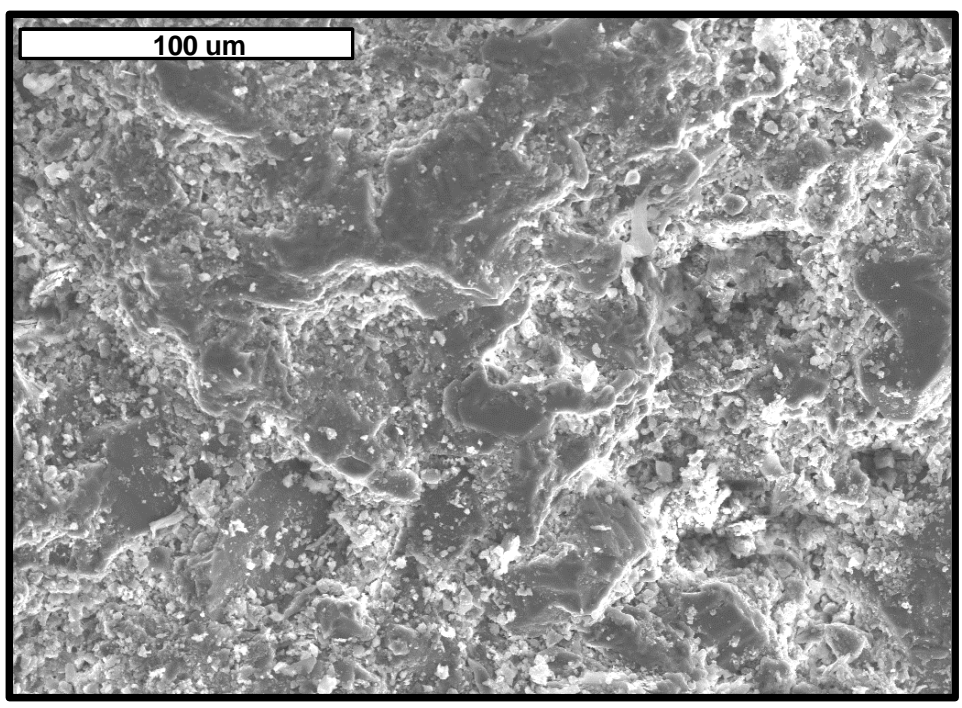

Figure 10. SEM photomicrograph of apparently unmineralized surface of a $5 \mathrm{U}$ fracture

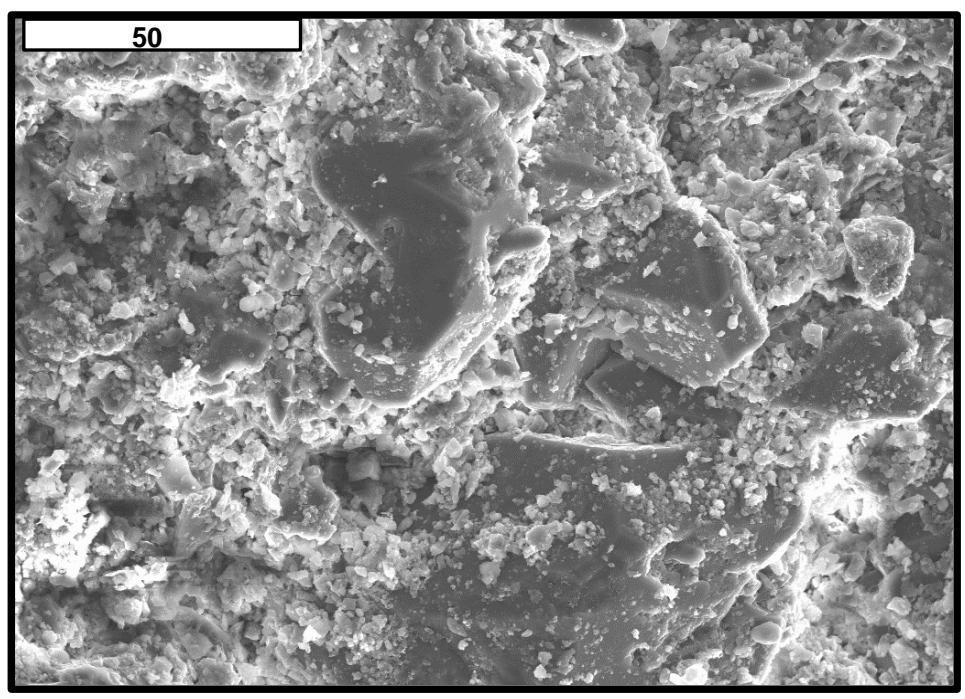

Figure 11. SEM photomicrograph of same surface in Fig. 10 at higher magnification. Note the presence of numerous euhedrallyterminated quartz crystals that apparently grew in the void space of the fracture. 
One cement type that was not seen in $1 \mathrm{U}$ fractures but that was seen in several $5 \mathrm{U}$ fractures of $\mathrm{N} 70 \mathrm{E}$ orientation was calcite (Fig. 12). SEM examination showed that calcite-encrusted surfaces tended to be somewhat rough and in some cases striations on surfaces were seen. Because the striations are in a variety of orientations, it is probable that they caused by dissolution along twin plane lamellae in calcite, rather than mechanical scratching from movement along fractures. Few crystals showed good euhedral terminations (Fig. 13). This may be either due to dissolution, or may indicate the lack of a significant amount of void space within fractures during crystal growth. An unmineralized N32E was found in one sample to terminate against a calcite-filled N70E fracture, indicating later formation for the N32Etrending fracture set. Calcite-filled fractures are also found in unoriented Middle Spraberry cores from other vertical wells drilled in the area. It is possible that the NE fracture set of the $1 \mathrm{U}$ is related to some fracture event that had a locus of activity within the middle Spraberry, or it may be that proximity to the carbonate-rich middle Spraberry enabled calcite precipitation only within lower parts of the upper Spraberry.

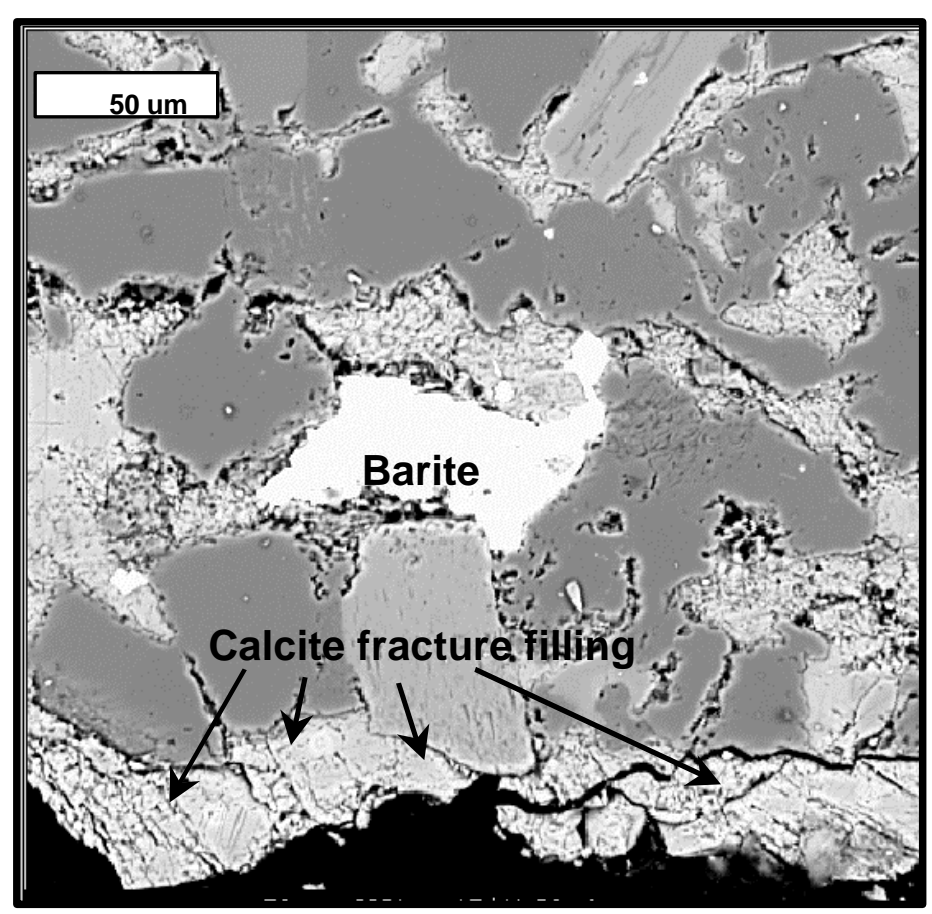

Figure 12. SEM

backscattered electron image of a polished thin section across a fracture. This 5U sample contains both barite as a pore-filling mineral and calcite as a fracture-filling phase. Calcite was also more abundant in pore spaces near calcite-filled fractures, and the calcitefilled fractures cut through previous diagenetic carbonate phases of dolomite, ferroan dolomite, and ankerite, showing that at least some fracturing occurred after these had been precipitated. 


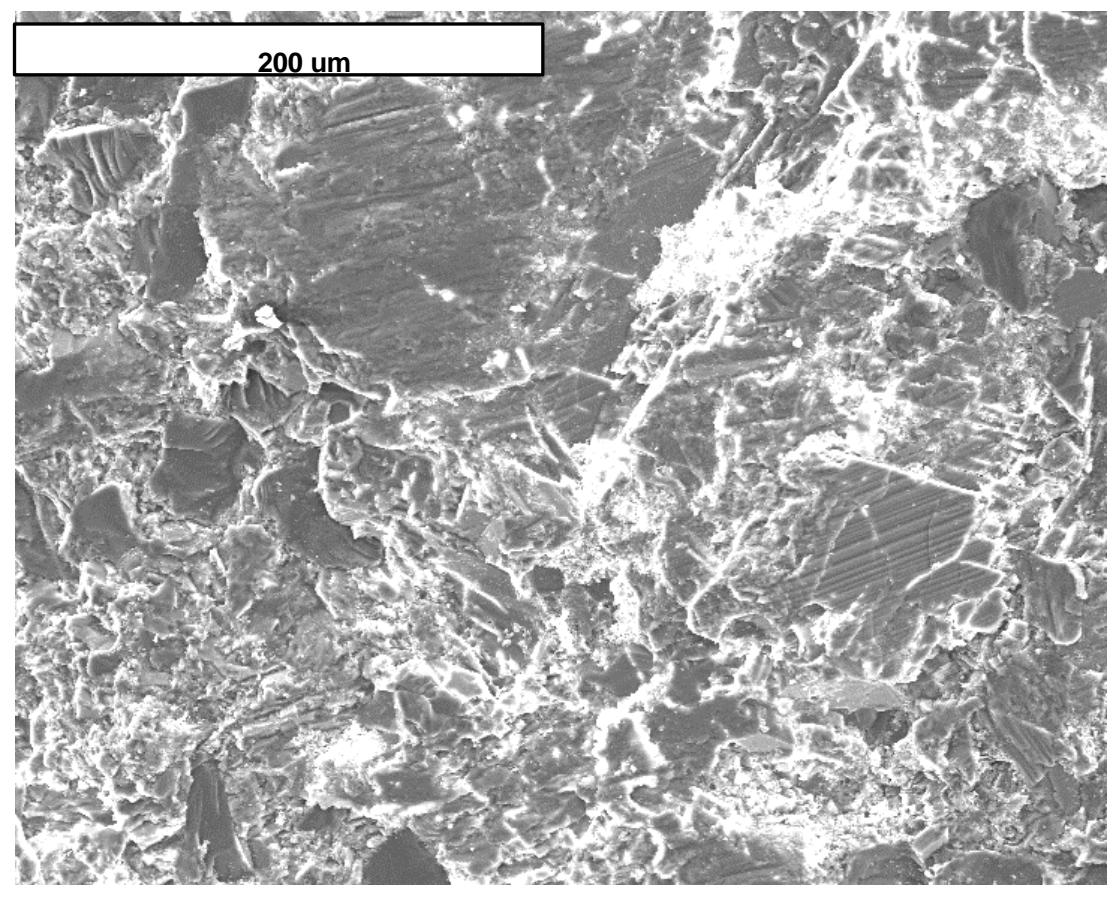

Figure 13. SEM photomicrograph of calcite crystals on the surface of a $5 \mathrm{U}$ fracture. Note the presence of striations on many crystal surfaces. These are believed to be due to dissolution along twin lamellae.

\section{EFFECTS OF MATRIX COMPOSITION ON FRACTURES}

Measurements of grain size and detrital composition were made in both $1 \mathrm{U}$ and $5 \mathrm{U}$ fractures to see if there was any affect of these factors on fracture distribution or mineralization. Additionally, we wanted to see if fracture mineralization had changed the rock matrix composition by dissolution or precipitation of additional cements. This work is still underway, but preliminary results suggest that there is no relationship between fracture distribution with either grain size or detrital composition. Within the $5 \mathrm{U}$ samples, there is locally more calcite cement in the rock matrix adjacent to the calcite-filled fractures. Calcite is relatively uncommon in most Spraberry siltstones, and most carbonate is dolomite, ferroan dolomite, or ankerite. Therefore, in at least a few instances, fracture diagenesis has altered the nearby rock matrix composition.

\section{PARAGENETIC SEQUENCES}

Table 1 shows a summary of the paragenetic sequences for $1 \mathrm{U}$ and $5 \mathrm{U}$ fractures. In the $1 \mathrm{U}$, fracturing is fairly straightforward. The N42E fracture set probably occurred first, as there is no barite mineralization within the few N80E fractures that were noted. Following fracturing, minor dolomite quartz precipitation occurred. There is no clear indication which mineral phase was precipitated first. Based on preliminary 
scanning catholodoluminescence studies (CL), it is believed that these cements were being precipitated both within the rock matrix and the fractures themselves contemporaneously. The barite was formed at a later time, shown by the fact that there is little or no barite noted within the rock matrix.

$5 \mathrm{U}$ fracture paragenesis is more complicated, as there are two sets of fractures. It is believed that the $\mathrm{N} 70 \mathrm{E}$ fracture set formed first, as there are a couple of examples of these fractures causing termination of N32E fractures. As in the 1U, diagenesis of matrix and fracture probably occurred near the same time. Later movement of fluids through the fractures caused at least local precipitation of calcite within fractures and nearby rock matrix. Evidence of some dissolution of calcite crystals within fractures demonstrates continued movement of fluid through these fractures. The N32E fracture set formed subsequent to this first fracture event, and there is minor precipitation of quartz and dolomite within these fractures. Barite precipitation probably occurred following the first fracture event, but there is not enough evidence to determine its relation to the second fracture event. The fact that it is not abundant in any $5 \mathrm{U}$ fractures and was only noted in samples containing N70E fractures suggests that it probably occurred between the two fracture events.

Table 1. Paragenetic Sequence for $1 \mathrm{U}$ and $5 \mathrm{U}$ units, Spraberry Fm., O’Daniel \#28 horizontal core.

\begin{tabular}{|c|c|}
\hline $1 \mathrm{U}$ fractures & $5 \mathrm{U}$ fractures \\
\hline - fracture formation & - fracture formation (NNE) \\
\hline - minor dolomite in fractures & - calcite mineralization \\
\hline - quartz mineralization & - fracture formation (ENE) \\
\hline \multirow[t]{3}{*}{ - barite mineralization } & - minor dolomite in fractures \\
\hline & - quartz mineralization \\
\hline & - barite mineralization \\
\hline
\end{tabular}


References

Lorenz, John C., 1997, Non-Congruent Natural Fracture Sets in Adjacent Beds at Depth: Data From Horizontal Cores from the Spraberry Formation, Midland Basin, TX, presented at: AAPG Hedberg

Research Conference, Reservoir Scale Deformation -Characterization and Prediction, June 22- 28, 1997, Bryce, Utah 
A possible sequence of events is shown in Fig. 14. The earliest stages of diagenesis and dolomitization were followed by a period of fracturing, possibly the N70E fracture set in the $5 \mathrm{U}$. The stresses or events that caused this fracture set may have been stronger deeper within the Spraberry, as suggested by the presence of calcite-filled fractures within the middle Spraberry and the 5U, but not within the $1 \mathrm{U}$. Precipitation of calcite cement within the N70E fractures followed. The next event was probably fracturing within the $1 \mathrm{U}$ that caused the $\mathrm{N} 42 \mathrm{E}$ fractures. At least three phases of carbonate are present in some $1 \mathrm{U}$ samples, with dolomite being the first-formed phase followed by ankerite, then a ferroan dolomite. (see Fig. 4). Ferroan dolomite is the most common phase seen within the $1 \mathrm{U}$ fractures. Nonluminescent quartz cement is seen both within fractures and rock matrix, suggesting that fracturing and precipitation of quartz and ferroan dolomite were occurring at the same time. Precipitation of barite within $1 \mathrm{U}$ fractures and possibly within the $5 \mathrm{U}$ followed. A third fracture event then affected the $5 \mathrm{U}$ and formed the N32E fractures. This event was the only that involved any obvious signs of incipient shear stress; the other fractures are solely tension-type fractures. Precipitation of quartz and dolomite within this fracture set then followed.

\section{Paragenetic Sequence for Spraberry Fractures}

\section{Early diagenesis \& dolomitization}

N70E fractures in $5 \mathrm{U}$

Precipitation of calcite in $5 \mathrm{U}$ fractures and matrix

-

Formation of N42E fractures in $1 \mathrm{U}$

Precipitation of quartz and ferroan dolomite in $1 \mathrm{U}$ and $5 \mathrm{U}$ fractures and matrix

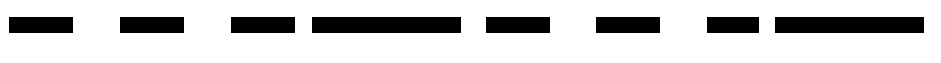

Barite precipitated in $1 \mathrm{U}$ fractures and $5 \mathrm{U}$ matrix

Formation of N32E fractures

Figure 14. Diagram showing the relative timing of diagenetic events that affected the upper Spraberry. 